\title{
Article \\ Effects of Preharvest Methyl Jasmonate Elicitation and Electrical Stimulation on Camptothecin Production by In Vitro Plants of Ophiorrhiza ridleyana Craib
}

\author{
Supakit Pisitpaibool ${ }^{1}$, Suchada Sukrong ${ }^{2, *} \mathbb{C}$, Kijchai Kanjanaprapakul ${ }^{3}$ and Muenduen Phisalaphong $1,3, *(\mathbb{D}$ \\ 1 Biomedical Engineering Program, Faculty of Engineering, Chulalongkorn University, \\ Bangkok 10330, Thailand; heng072@hotmail.com \\ 2 Research Unit of DNA Barcoding of Thai Medicinal Plants, Department of Pharmacognosy and \\ Pharmaceutical Botany, Faculty of Pharmaceutical Sciences, Chulalongkorn University, \\ Bangkok 10330, Thailand \\ 3 Department of Chemical Engineering, Faculty of Engineering, Chulalongkorn University, \\ Bangkok 10330, Thailand; kitchai.k@chula.ac.th \\ * Correspondence: Suchada.Su@chula.ac.th (S.S.); Muenduen.P@chula.ac.th (M.P.)
}

check for updates

Citation: Pisitpaibool, S.; Sukrong, S.; Kanjanaprapakul, K.; Phisalaphong, M. Effects of Preharvest Methyl Jasmonate Elicitation and Electrical Stimulation on Camptothecin Production by In Vitro Plants of Ophiorrhiza ridleyana Craib. Appl. Sci. 2021, 11, 4555. https://doi.org/ 10.3390/app11104555

Received: 26 March 2021

Accepted: 11 May 2021

Published: 17 May 2021

Publisher's Note: MDPI stays neutral with regard to jurisdictional claims in published maps and institutional affiliations.

Copyright: (c) 2021 by the authors. Licensee MDPI, Basel, Switzerland. This article is an open access article distributed under the terms and conditions of the Creative Commons Attribution (CC BY) license (https:// creativecommons.org/licenses/by/ $4.0 /)$.

\begin{abstract}
To enhance plant camptothecin (CPT) production in vitro, 5-month-old Ophiorrhiza ridleyana Craib plant cultures were treated with solutions of methyl jasmonate (MeJA) dissolved in ethanol, which were applied to the surface of the solid culture medium. It was demonstrated that the maximum CPT content in the tissue-cultured plants was achieved after $12 \mathrm{~h}$ elicitation with $50 \mu \mathrm{M}$ MeJA. The mean CPT contents in roots and stems were 50.8 and $67.0 \mu \mathrm{g} / \mathrm{g}$ DW, respectively, which were approximately 1.8- and 2.6-fold higher, respectively, than those of the control. However, MeJA elicitation showed no significant effect on CPT accumulation in O. ridleyana leaves. Moreover, it was found that direct electric current (DC) stimulation also significantly increased CPT accumulation in O. ridleyana. The treatment with DC at $20 \mathrm{~mA}$ for $3 \mathrm{~min}$ of stimulation enhanced 3-fold the CPT content in roots, stems, and leaves to $41.9,36.0$ and $19.6 \mu \mathrm{g} / \mathrm{g}$ DW, respectively, which were approximately 1.5-, 1.7- and 1.4-fold higher, respectively, as compared to those of the control. The results demonstrate that preharvest treatment by MeJA elicitation and electrical stimulation can be beneficial for secondary metabolite production of CPT in tissue-culture plants of $O$. ridleyana.
\end{abstract}

Keywords: camptothecin; Ophiorrhiza ridleyana; in vitro plants; elicitation; methyl jasmonate; electrical stimulation

\section{Introduction}

Camptothecin (CPT) is a pentacyclic monoterpene indole alkaloid with anticancer properties, originally identified from the bark extracts of the Chinese tree Camptotheca acuminata (Nyssaceae) by Wall et al. in 1966 [1-3]. Camptothecin showed low solubility in water and toxicity during clinical trials [4,5], therefore the compound has not been used directly in practice owing to its side effects. However, semi-synthetic derivatives of CPTtopotecan and irinotecan-have been approved by the U.S. Food and Drug Administration for use as anticancer drugs and are widely prescribed in the treatment of ovarian, colorectal and small-cell lung cancer. The anticancer activity of CPT and its derivatives is due to the property of reversible binding to the topoisomerase I-DNA complex in cancer cells, thereby inhibiting DNA replication and triggering cancer cell death [6,7]. Other medicinal properties of CPT and its related derivatives include antiviral properties, pesticide activity, and antiparasitic activity [8].

Given the desirable pharmacological activities of CPT derivatives, the global market for CPT analogs from natural sources has increased rapidly, which has caused a decline in wild plant populations. This has led to the search for alternative sources and in vitro culture methods for CPT production $[9,10]$. A biotechnological method, employing plant cell 
culture technology, is a promising alternative strategy [11]. The production of secondary metabolites by genetically engineered plant cell culture has become an important topic because of a shortage of natural resources and subsequent environmental concerns [1]. Recently, tissue-culture CPT-producing Ophiorrhiza (Rubiaceae) species have attracted attention as alternative sources for CPT production [12]. Camptothecin is synthesized by a number of Ophiorrhiza species, e.g., O. liukiuensis and O. kuroiwai [4], O. prostrata [13], O. alata [10], O. pumila [14], and O. mungos [5].

One approach to promote plant tissue metabolism is by using elicitors [15]. The treatment of plant cells with biotic elicitors, such as bacterial and fungal cell walls, yeast extract and microbial homogenate, or abiotic elicitors, such as jasmonic acid and methyl jasmonate (MeJA), is a useful strategy to enhance production in cell/organ cultures of secondary metabolites, such as terpenoids, flavonoids, phenolic, alkaloids, and phytoalexins [16-18]. Methyl jasmonate and its derivatives are important signal transduction molecules widely used as elicitor compounds for induction of secondary metabolites in many plant species and in plant cell and callus cultures $[19,20]$. Enhanced accumulation of secondary metabolites in in vitro culture systems using MeJA has been frequently reported. Methyl jasmonate acts as a signal transducer to promote in vitro production of CPT from multiple shoots of O. mungos var. angustifolia in liquid culture medium [21]. The in vitro production of the secondary metabolite plumbagin in roots and shoots of Drosera burmanii in half-strength Murashige and Skoog ( $1 / 2 \mathrm{MS})$ liquid medium was enhanced after elicitation for $6 \mathrm{~d}$ with $50 \mu \mathrm{M}$ MeJA [22]. In addition, preharvest MeJA application to 2-year-old raspberry and blackcurrant plants as a foliar spray significantly increased the synthesis of flavonoids, particularly, ellagic acid, quercetin and myricetin [23].

Accumulation of secondary plant compounds can also be induced by physiologyelectrical stimulation. Electrical stimulation has shown to have effects on living cells, including plant cells. Pulsed electric field treatment is a promising tool to induce various biological effects for cellular compound stimulation [24]. However, research on the effects of electricity on plant response is quite limited. Electric current is a flow of electric charge carried by moving electrons through conductors or semiconductors or by ion in an electrolyte, which is measured in ampere (A) [25]. Electricity is found to have an influence on growth and the secondary metabolism in plants. It was demonstrated that pulsed electric field stimulated plant secondary metabolism in suspension cultures of Taxus chinensis [26]. Direct-electric-current (DC) intensities between 100 and $500 \mathrm{~mA}$ with applications of 15 to 60 min enhanced the accumulation of carotenoids, phenolic compounds in tomatoes [27]. The application of DC with a voltage of 8 and $16 \mathrm{~V}, 10 \mathrm{~h} /$ day for 12 days could promote growth and bioactive compounds of African nightshade (Solanum scabrum Mill.) plants, in which applying DC was found to increase leaf fresh and dry weight and enhance biosynthesis of chlorophylls and carotenoids [28]. Pulsed electric fields pre-treatment on grapes enhanced the release of the major anthocyanin found in Pinot Noir, i.e., malvidin-3-Oglucoside and thus promoted the accumulation of total phenolic and vitamin $\mathrm{C}$ as well as the improvement in the 2,2-diphenyl-1-picryhydrazyl (DPPH) radical scavenging activity and bioprotective capacity [29]. However until now, no study has been done for the effect of electrical stimulation on CPT production/accumulation in plants or plant tissue cultures.

In the present study, we developed elicitation techniques to stimulate CPT production in vitro in 5-month-old plants of $O$. ridleyana cultured in solid medium. The effects of MeJA elicitation and electrical stimulation by DC current on CPT production in roots, stems and leaves of treated O. ridleyana were investigated in order to develop practical methods to generate a higher yielding source of CPT from tissue-culture plants.

\section{Materials and Methods}

\subsection{Plant Materials}

Ophiorrhiza ridleyana plants with seeds were collected from Chang Island, Trat Province, Thailand. All voucher specimens collected from plants for research were preserved at the Museum of Natural Medicines, Faculty of Pharmaceutical Sciences, Chulalongkorn 
University, Thailand. Plants were identified by an experienced botanist, Associate Professor Thatree Phadungcharoen at Chulalongkorn University.

\subsection{Culture of Aseptic Plants}

Ophiorrhiza ridleyana seeds were soaked with running tap water for $1 \mathrm{~h}$, surfacesterilized in $70 \%$ ethanol for $1 \mathrm{~min}$ and then in $1 \%$ sodium hypochlorite (Clorox ${ }^{\circledR}$ ) with the addition of two drops of Tween- 20 and shaken $15 \mathrm{~min}$. The sterilized seeds were washed three times with sterile distilled water for $5 \mathrm{~min}$ each. The seeds were germinated on $1 / 2$ MS solid medium supplemented with $2 \%$ sucrose and $0.8 \%$ agar. The medium $\mathrm{pH}$ was adjusted to 5.7 prior to autoclaving at $121^{\circ} \mathrm{C}$ and $1.2 \mathrm{~kg} \mathrm{~cm}^{-2}$ pressure for $20 \mathrm{~min}$. All aseptic plants were cultured in the prepared solid medium at $25^{\circ} \mathrm{C}$ under a $16 \mathrm{~h} / 8 \mathrm{~h}$ (light/dark) photoperiod. Plantlets were used as material for shoot induction.

\subsection{Shoot Induction}

Stem segments from in vitro plantlets were cultured in $\frac{1}{2}$ MS solid medium for shoot multiplication. The seeds germinated after 4 weeks. The plantlets were subcultured on fresh medium every four weeks for shoot elongation. Eight weeks after germination, the seedlings had developed a single shoot with 2-4 true leaves and roots. Shoots approximately $1 \mathrm{~cm}$ in length were excised and used as shoot explant. The explants were subcultured on the same solid medium in a $30 \mathrm{~mL}$ culture bottle for elicitor treatment.

\subsection{Elicitation Treatment}

Aseptic plants of $O$. ridleyana were subcultured by transferring the shoot explants to $1 / 2 \mathrm{MS}$ solid medium, which were cultured under a photoperiod of $16 \mathrm{~h} / 8 \mathrm{~h}$ (light/dark). The explants were cultured for 5 months (Figure 1) so as to develop sufficient roots for chemical analysis. In vitro plants of 5-month-old O. ridleyana were treated with MeJA solution. The MeJA solution was gently and thoroughly poured onto the surface of the solid medium in each culture bottle using sterile pipette tip. Four concentrations of MeJA $(0,20,50$ and $100 \mu \mathrm{M})$ in $0.2 \mathrm{~mL}$ ethanol were used for the elicitor treatment. The culture bottles were incubated with the elicitor for 12 and $24 \mathrm{~h}$ at $25^{\circ} \mathrm{C}$. Controls were cultured under the same condition but without addition of an elicitor to the culture bottle. The elicitor treatment with $0 \mu \mathrm{M}$ MeJA used pure ethanol as an elicitor. Each experiment was performed in triplicate.

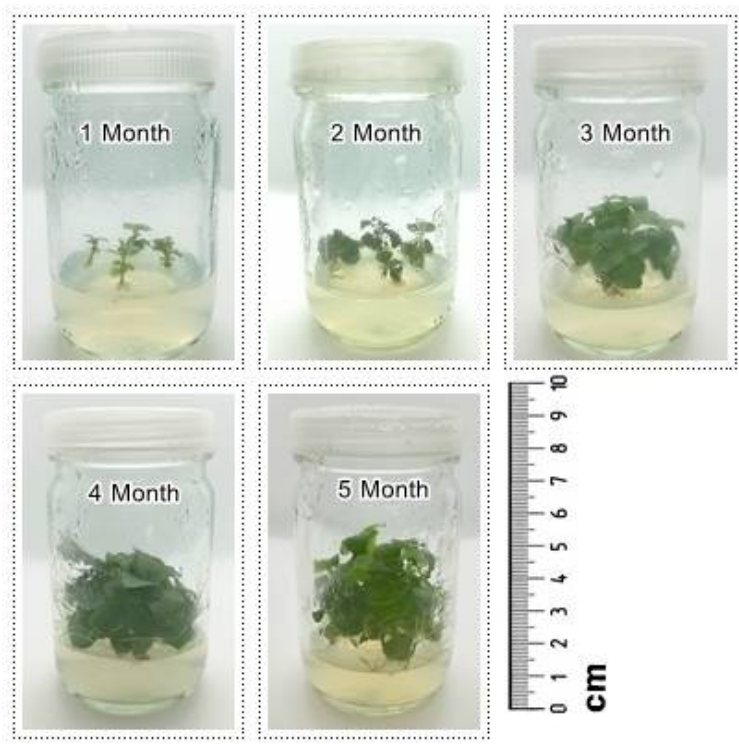

Figure 1. Tissue culture plants of O. ridleyana in half strength MS medium after cultivation for 1-5 months. 


\subsection{Direct-Electric-Current Treatment}

The 5 month-old tissue culture plants of $O$. ridleyana in a $30 \mathrm{~mL}$ culture bottle were treated with four different DC currents $(10,20,30$ and $40 \mathrm{~mA}$ ) by electrical stimulator (Wanptek KPS1203D Switching DC Power Supply, Overwin Electronic Source Company Limited, Bangkok, Thailand) as shown in Figure 2. The electric current flowed through the solid medium by passing through a solid stainless bar of thickness $0.031 \mathrm{~cm}$, width $1.40 \mathrm{~cm}$ and length $11.50 \mathrm{~cm}$. Total treatment time is $15 \mathrm{~min}$, which was divided into 3 cycles. Each cycle took $5 \mathrm{~min}$, performed by supplying electricity for $3 \mathrm{~min}$ and cutting off the electricity for $2 \mathrm{~min}$. After the DC treatment, the treated culture bottles were incubated for $24 \mathrm{~h}$ at $25^{\circ} \mathrm{C}$, before the tissue culture plants were taken for the analysis of CPT concentration. Controls were the tissue cultured plants cultured under the same condition but without the electrical stimulation. Each experiment was performed in triplicate.

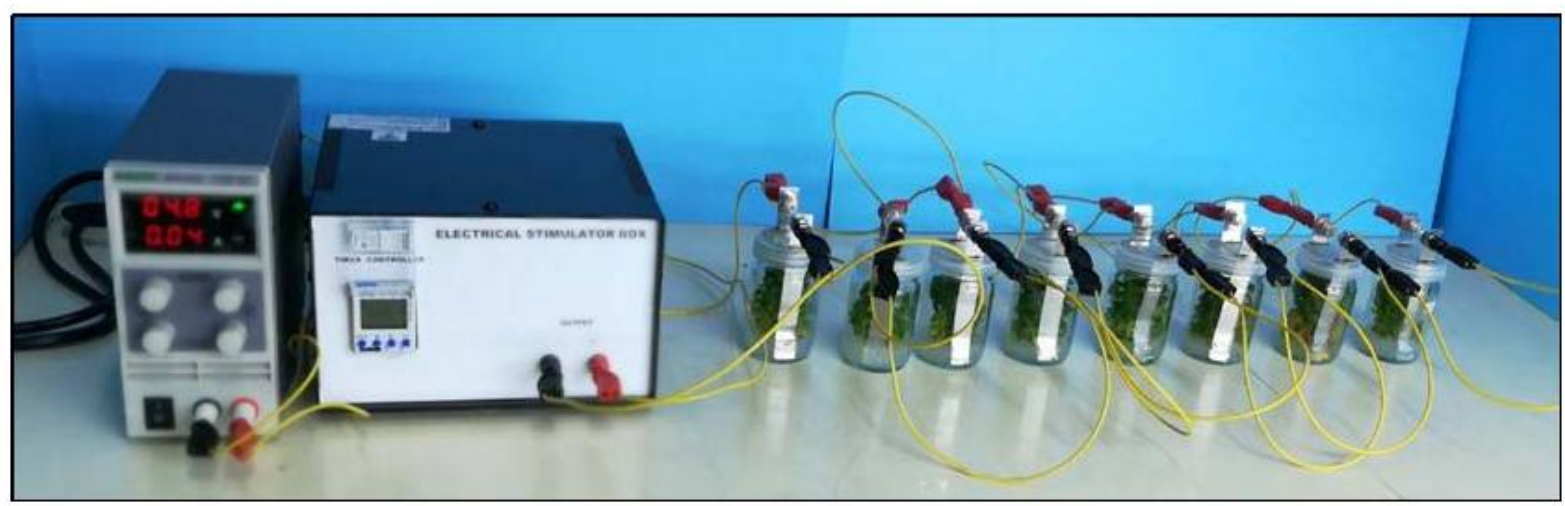

Figure 2. Experimental study for electrical stimulation on 5-month-old tissue culture plants of $O$. ridleyana.

\subsection{Camptothecin (CPT) Analysis}

The quantitative analysis of CPT in the leaves, stems and roots in vitro culture was performed according to a previously reported procedure with minor modifications $[10,13]$ by using Agilent HPLC 1260 Infinity II LC System (Santa Clara, CA, USA). For CPT extraction, plant samples were dissected into leaves, stems and roots. The samples were freeze-dried at $-90{ }^{\circ} \mathrm{C}$ for $72 \mathrm{~h}$. The freeze-dried samples were ground into powder for further analysis. A sample of powder $(15 \mathrm{mg})$ was placed in a $1.5 \mathrm{~mL}$ tube to which $0.5 \mathrm{~mL}$ methanol was added. The mixture was placed in an ultrasonic bath for $30 \mathrm{~min}$ at room temperature $\left(30^{\circ} \mathrm{C}\right)$ and incubated at $4{ }^{\circ} \mathrm{C}$ overnight. The homogenates were centrifuged at $12,000 \times g$ for $5 \mathrm{~min}$. The supernatants were filtered through a $0.45 \mu \mathrm{m}$ syringe filter for high-performance liquid chromatography (HPLC) analysis. For quantification, a calibration curve for standard CPT was prepared. The standard CPT (Sigma Chemical Co., St Louis, MO, USA) was dissolved in dimethyl sulfoxide and diluted to generate a concentration series of $5-50 \mu \mathrm{g} / \mathrm{mL}$. For separation by HPLC, a Zorbax Eclipse Plus C18 column $(4.6 \times 250 \mathrm{mM}, 5 \mu \mathrm{m})$ (Agilent Technologies) with a mobile phase of acetonitrile:water (3:7) was used. The flow rate was $1 \mathrm{~mL} / \mathrm{min}$ and the injection volume was $20 \mu \mathrm{L}$. The CPT detection wavelength was set at $254 \mathrm{~nm}$. The peak identification was performed by comparing the peak's retention time with that of injected reference standard of CPT in the same chromatographic system. The quantity of CPT in the samples was estimated based on standard curve quantitation by a CPT standard, using area under the curve. Data analysis was performed by using Agilent ChemStation software.

\subsection{Statistical Analysis}

All the experiments were repeated in triplicate (three culture bottles) under the same conditions and values were expressed as the mean \pm standard deviation (SD). The data were analyzed by variance (ANOVA) followed by Duncan post hoc test to compare means $(p \leq 0.05)$ using the SPSS Statistics 17 software (SPSS Inc., Chicago, IL, USA). 


\section{Results}

\subsection{Accumulation of CPT in 5-Month-Old O. ridleyana Plant Cultures}

The biomass of fresh and dry weights in different parts of 5-month-old tissue culture plants of $O$. ridleyana in a $30 \mathrm{~mL}$ culture bottle is shown in Table 1 . The accumulation of $\mathrm{CPT}$ in the roots, stems, and leaves of 5-month-old tissue-culture plants of $O$. ridleyana without elicitor treatment is shown in Figure 3 and Table 2. The highest CPT content was recorded in the roots $(0.0028 \%$ dry weight $(\mathrm{DW}))$, followed by the stems $(0.0025 \% \mathrm{DW})$ and the leaves $(0.0013 \% \mathrm{DW})$. It should be noted that, the amount of CPT produced by leaf was significantly lower than that produced by root and stem, however the biomass of leaf was considerably higher as compared to root and stem.

Table 1. Biomass of fresh and dry weights in different parts of 5-month-old tissue culture plants of O. ridleyana in a $30 \mathrm{~mL}$ culture bottle.

\begin{tabular}{ccc}
\hline \multirow{2}{*}{ Plant Part } & \multicolumn{2}{c}{ Biomass } \\
\cline { 2 - 3 } & Average Fresh Weight (mg) & Average Dry Weight (mg) \\
\hline Root & $178.7 \pm 81.0$ & $54.2 \pm 48.7$ \\
Stem & $786.7 \pm 186.1$ & $67.0 \pm 8.3$ \\
Leaf & $1023.0 \pm 182.0$ & $191.9 \pm 9.2$ \\
\hline
\end{tabular}
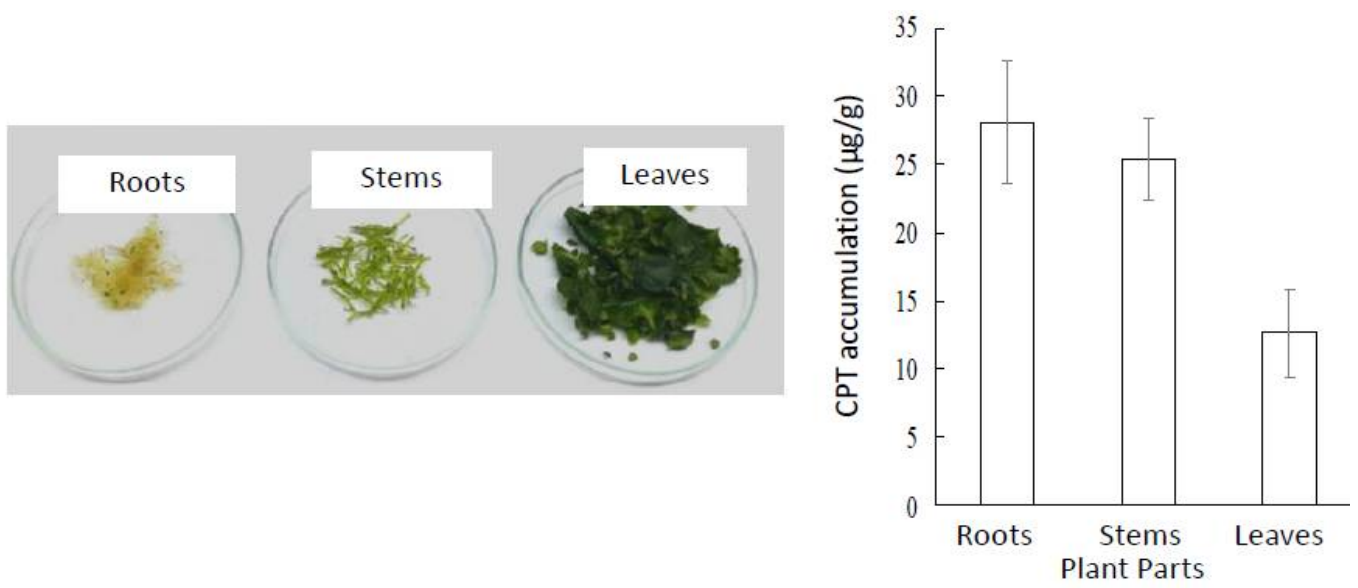

Figure 3. Distribution of CPT accumulation in roots, stems and leaves of 5-month-old tissue culture plants of O. ridleyana. The values are expressed as mean $\pm \operatorname{SD}(n=3)$.

Table 2. Average CPT concentrations in different parts of 5-month-old tissue culture plants of O. ridleyana treated with MeJA in ethanol $(0-100 \mu \mathrm{M})$.

\begin{tabular}{ccccc}
\hline \multirow{2}{*}{ Treatment } & \multirow{2}{*}{ Incubation Time (h) } & \multicolumn{3}{c}{ CPT Content $(\mu \mathrm{g} / \mathbf{g}$ DW) } \\
\cline { 3 - 5 } & & Root & Stem & Leaf \\
\hline Control & - & $28.1 \pm 4.0$ & $25.4 \pm 3.0$ & $12.7 \pm 3.3$ \\
\hline Ethanol & 12 & $31.4 \pm 3.0$ & $24.4 \pm 2.1$ & $12.7 \pm 2.6$ \\
& 24 & $26.5 \pm 2.8$ & $21.2 \pm 2.8$ & $13.4 \pm 2.7$ \\
\hline MeJA $20 \mu \mathrm{M}$ & 12 & $35.5 \pm 3.2^{\text {a }}$ & $24.9 \pm 4.3$ & $14.3 \pm 1.7$ \\
& 24 & $34.2 \pm 2.6^{\text {a }}$ & $29.0 \pm 3.3$ & $14.0 \pm 2.9$ \\
\hline MeJA $50 \mu \mathrm{M}$ & 12 & $50.8 \pm 4.3^{\text {a }}$ & $67.0 \pm 5.8^{\text {a }}$ & $15.9 \pm 2.8$ \\
& 24 & $33.8 \pm 3.9$ & $48.9 \pm 2.6^{\text {a }}$ & $13.9 \pm 2.0$ \\
\hline MeJA $100 \mu \mathrm{M}$ & 12 & $31.3 \pm 1.0$ & $25.4 \pm 4.0$ & $11.8 \pm 2.2$ \\
\hline a: significant at $p<0.05$ vs. control. & & &
\end{tabular}

a: significant at $p<0.05$ vs. control. 


\subsection{Effect of MeJA Elicitation on CPT Accumulation in O. ridleyana}

\subsubsection{Roots}

As compared to the control, accumulation of CPT in the roots to some extent increased after 12-24 h exposure to 20-100 $\mu \mathrm{M}$ MeJA (Figure 4). Higher CPT contents were observed in response to MeJA elicitation for $12 \mathrm{~h}$ compared with elicitation to $24 \mathrm{~h}$, except for $100 \mu \mathrm{M}$ MeJA treatment. The optimal elicitor concentration was $50 \mu \mathrm{M}$ MeJA. No significant increase was observed by pure ethanol $(0 \mu \mathrm{M}$ MeJA $)$ as an elicitor. The HPLC chromatograms obtained from extracts of roots of $O$. ridleyana treated with $50 \mu \mathrm{M}$ MeJA for $12 \mathrm{~h}$ showed a much larger peak area than those of the untreated controls (Supplementary Materials), in which the maximum CPT content represented approximately 1.8-fold increase compared with that of the controls. However, only a slight increase in CPT content was observed in response to elicitation with a higher MeJA concentration at $100 \mu \mathrm{M}$.

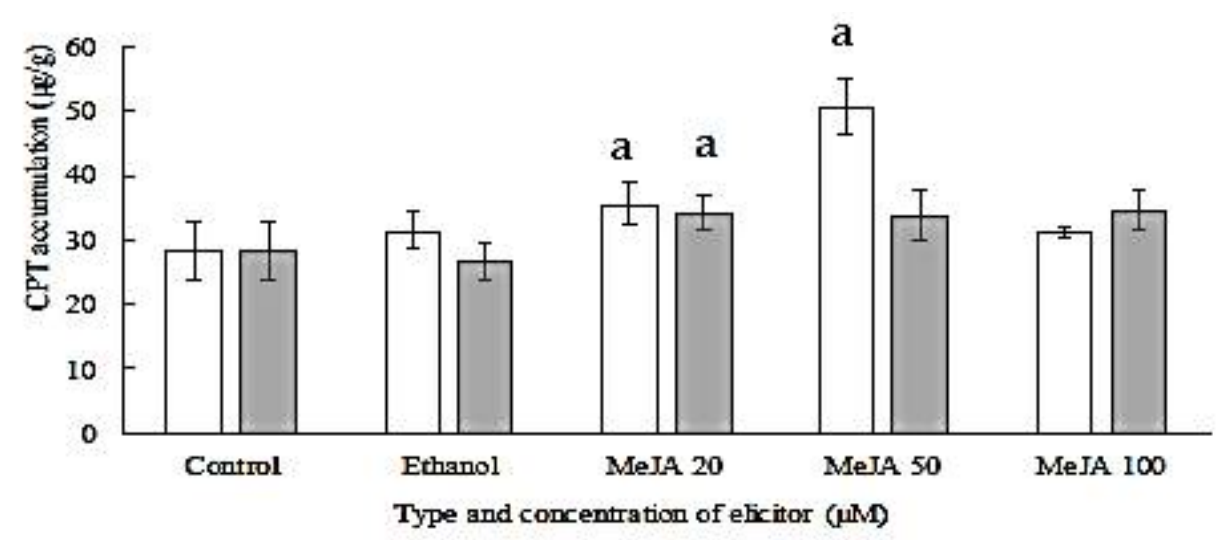

Figure 4. Effects of MeJA elicitation on CPT concentration in roots by elicitation with ethanol and MeJA (20, 50 and $100 \mu \mathrm{M})$ for $12 \mathrm{~h}(\square)$ and $24 \mathrm{~h}(\boldsymbol{\square})$ before harvesting. The values are expressed as mean $\pm \mathrm{SD}(n=3)$; a: significant at $p<0.05$ vs. control.

\subsubsection{Stems}

Following $50 \mu \mathrm{M}$ MeJA elicitation for 12 and $24 \mathrm{~h}$, the CPT content in the stems of $O$. ridleyana increased significantly (Figure 5). The maximum CPT content in the stems in response to MeJA elicitation was increased by 2.6 -fold $(66.98 \mu \mathrm{g} / \mathrm{g} \mathrm{DW})$ and 1.9 -fold $(48.85 \mu \mathrm{g} / \mathrm{g} \mathrm{DW})$ after MeJA treatment for 12 and $24 \mathrm{~h}$, respectively. No significant effect of elicitation with ethanol, 20 and $100 \mu \mathrm{M}$ MeJA on CPT content in O. ridleyana stems was observed.

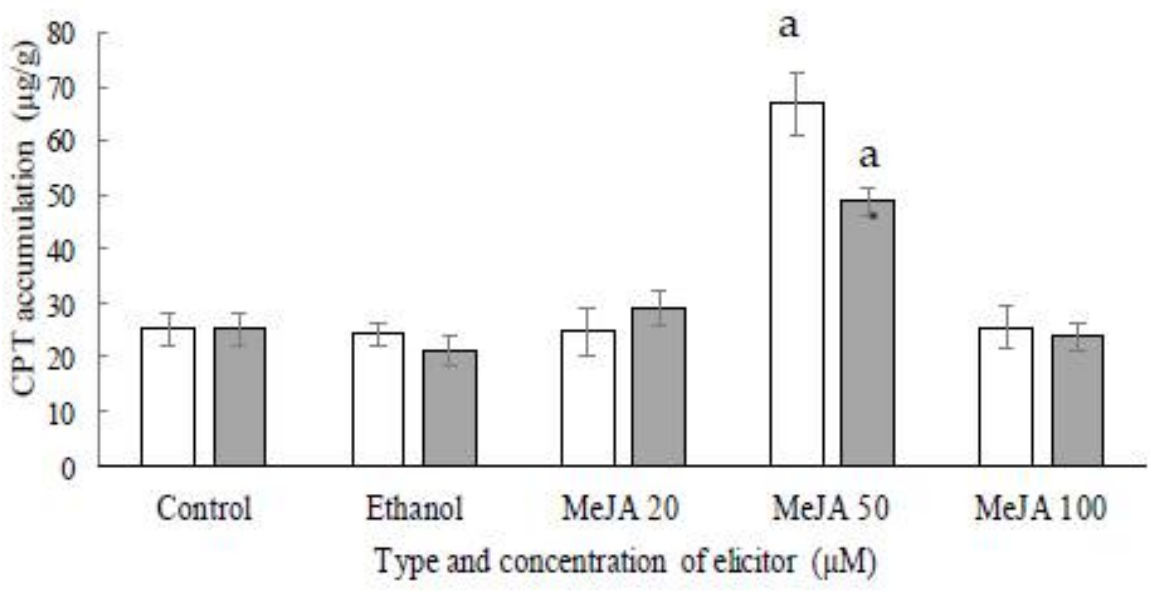

Figure 5. Effects of MeJA elicitation on CPT concentration in stems by elicitation with ethanol and MeJA (20, 50 and $100 \mu \mathrm{M})$ for $12 \mathrm{~h}(\square)$ and $24 \mathrm{~h}(\mathbf{\square})$ before harvesting. The values are expressed as mean $\pm \mathrm{SD}(n=3)$; a: significant at $p<0.05$ vs. control. 


\subsubsection{Leaves}

Overall, the CPT content in O. ridleyana leaves was lower than those in the roots and stems. No significant effect of MeJA and ethanol elicitation on CPT accumulation in O. ridleyana leaves was detected. Under the 20 and $50 \mu \mathrm{M}$ MeJA treatments, only slight increases in CPT content in the leaves was observed (Figure 6).

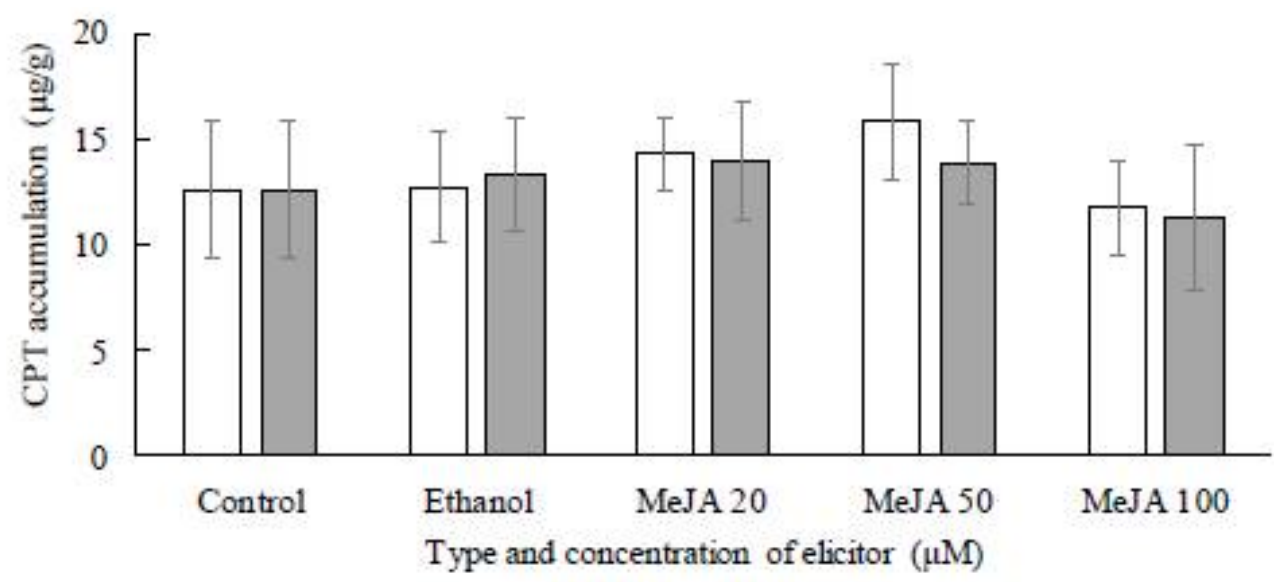

Figure 6. Effects of MeJA elicitation on CPT concentration in leaves by elicitation with ethanol and MeJA $(20,50$ and $100 \mu \mathrm{M})$ for $12 \mathrm{~h}(\square)$ and $24 \mathrm{~h}(\boldsymbol{\square})$ before harvesting. The values are expressed as mean $\pm \operatorname{SD}(n=3)$.

\subsubsection{Total CPT Accumulation in Tissue Culture Plants}

The fresh weight ratio of root:stem:leaf was about 1:4.4:5.7 and the corresponding DW ratio was 1:1.2:3.5. The moisture contents of the root, stem and leaf of 5-month-old tissueculture plants were $69.67 \%, 91.48 \%$, and $81.24 \%$, respectively. The CPT concentrations in the root, stem, and leaf of 5-month-old O. ridleyana after elicitation treatment for 12 and $24 \mathrm{~h}$ was analyzed by HPLC (Table 2). In this study, no significant difference in CPT accumulation in the root, stem, and leaf was observed in response to elicitation with ethanol. However, significant increases in CPT content in the root and stem were detected following MeJA elicitations, particularly with $50 \mu \mathrm{M}$ MeJA. However, no significant difference in $\mathrm{CPT}$ content in the leaves was observed after elicitation with MeJA. After $50 \mu \mathrm{M}$ MeJA elicitation for $12 \mathrm{~h}$, the highest contents of CPT observed in stems, roots, and leaves were $66.98,50.79$ and $15.85 \mu \mathrm{g} / \mathrm{g}$ DW, respectively. Base on the average biomass (Table 1) and average CPT contents (Table 2), the CPT accumulation of 5-month-old tissue-culture plants of $O$. ridleyana treated with MeJA of $0-100 \mu \mathrm{M}$ in ethanol was calculated (Table 3). The CPT content in the root and stem elicited with $50 \mu \mathrm{M}$ MeJA for $12 \mathrm{~h}$ was 1.8- and 2.6-fold higher than that of the controls, respectively.

\subsection{Effect of Electrical Stimulation on CPT Accumulation in O. ridleyana}

\subsubsection{Roots}

The present study indicated an influence of DC intensity on CPT accumulation in plant cultures of $O$. ridleyana. Roots of 5-month-old tissue culture plants of $O$. ridleyana had higher CPT contents compared with stems and leaves. Average CPT concentrations in different parts of $O$. ridleyana treated with DC current at 10-40 mA are shown in Table 4 . The DC stimulation resulted in significant increases in CPT content in all parts of the tissue culture plants (Table 4 and Figures 7-9). The highest CPT content in roots at $41.9 \mu \mathrm{g} / \mathrm{g} \mathrm{DW}$ was obtained from the stimulation by the DC current at $20 \mathrm{~mA}$, followed by the stimulation at $30 \mathrm{~mA}, 40 \mathrm{~mA}$ and $10 \mathrm{~mA}$, respectively. 
Table 3. The estimated CPT content per $30 \mathrm{~mL}$ culture bottle of 5 -month-old tissue culture plants of O. ridleyana treated with MeJA in ethanol $(0-100 \mu \mathrm{M})$ compared to the control.

\begin{tabular}{cccccc}
\hline \multirow{2}{*}{ Treatment } & \multirow{2}{*}{ Incubation Time $(\mathbf{h})$} & \multicolumn{4}{c}{ CPT $^{\text {a }}$ Content $(\mu \mathrm{g} /$ Culture Bottle) } \\
\cline { 3 - 5 } & & Root & Stem & Leaf & Total \\
\hline Control & - & 1.5 & 1.7 & 2.4 & 5.7 \\
\hline Ethanol & 12 & 1.7 & 1.6 & 2.4 & 5.8 \\
& 24 & 1.4 & 1.4 & 2.6 & 5.4 \\
\hline MeJA $20 \mu \mathrm{M}$ & 12 & 1.9 & 1.7 & 2.7 & 6.3 \\
& 24 & 1.9 & 1.9 & 2.7 & 6.5 \\
\hline \multirow{2}{*}{ MeJA $50 \mu \mathrm{M}$} & 12 & 2.8 & 4.5 & 3.0 & 10.3 \\
& 24 & 1.8 & 3.3 & 2.7 & 7.8 \\
\hline MeJA $100 \mu \mathrm{M}$ & 12 & 1.7 & 1.7 & 2.3 & 5.7 \\
& 24 & 1.9 & 1.6 & 2.2 & 5.7 \\
\hline
\end{tabular}

a: calculation by using the average dry weight in Table 1.

Table 4. Average CPT concentrations in different parts of 5-month-old tissue culture plants of $O$. ridleyana treated with DC current at 10-40 mA and the estimated CPT content per $30 \mathrm{~mL}$ culture bottle.

\begin{tabular}{cccccccc}
\hline \multirow{2}{*}{ Treatment } & \multicolumn{3}{c}{ CPT Content $(\mu \mathrm{g} / \mathrm{g}$ DW) } & \multicolumn{3}{c}{ CPT Content ${ }^{\mathbf{b}}(\mu \mathrm{g} /$ Culture Bottle) } \\
\cline { 2 - 8 } & Root & Stem & Leaf & Root & Stem & Leaf & Total \\
\hline Control & $27.3 \pm 1.3$ & $21.3 \pm 3.0$ & $13.8 \pm 2.7$ & 1.5 & 1.4 & 2.6 & 5.5 \\
DC 10 mA & $33.5 \pm 3.8^{\text {a }}$ & $24.9 \pm 3.5$ & $15.9 \pm 2.9$ & 1.8 & 1.7 & 3.1 & 6.5 \\
DC 20 mA & $41.9 \pm 2.7^{\text {a }}$ & $36.0 \pm 2.7^{\text {a }}$ & $19.6 \pm 2.1^{\text {a }}$ & 2.3 & 2.4 & 3.8 & 8.4 \\
DC 30 mA & $36.4 \pm 4^{\text {a }}$ & $31.8 \pm 2.4^{\text {a }}$ & $16.7 \pm 3.0$ & 2.0 & 2.1 & 3.2 & 7.3 \\
DC 40 mA & $34.7 \pm 3.3^{\text {a }}$ & $26.1 \pm 1.8$ & $16.0 \pm 3.4$ & 1.9 & 1.8 & 3.1 & 6.7 \\
\hline
\end{tabular}

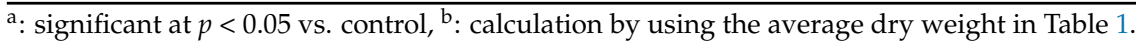

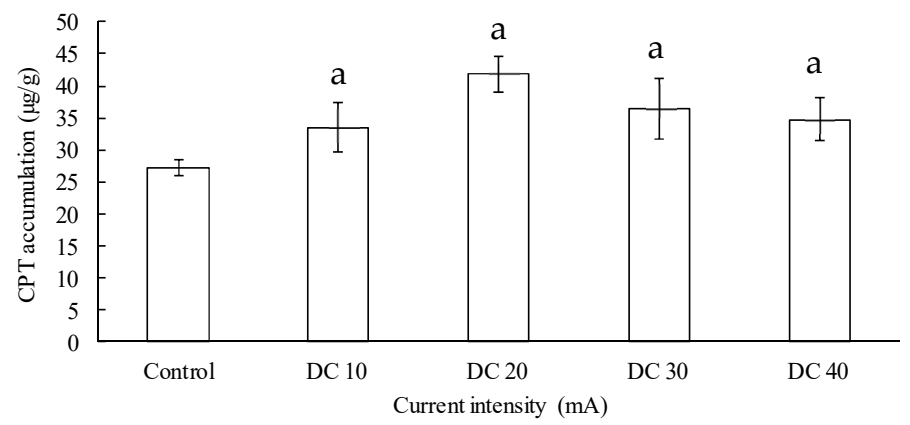

Figure 7. Effects of DC intensities (10, 20, 30 and $40 \mathrm{~mA})$ on CPT accumulation in O. ridleyana roots. The values are expressed as mean $\pm \mathrm{SD}(n=3)$; a: significant at $p<0.05$ vs. control.

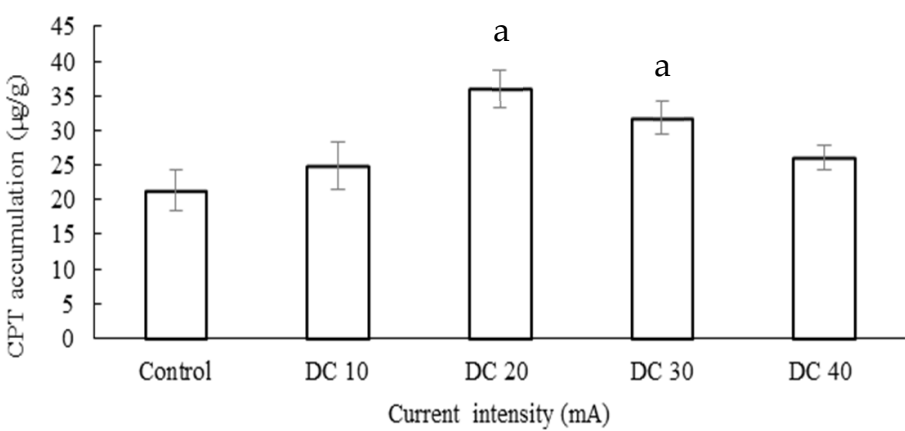

Figure 8. Effects of DC intensities (10, 20, 30 and $40 \mathrm{~mA})$ on CPT accumulation in O. ridleyana stems. The values are expressed as mean $\pm \mathrm{SD}(n=3)$; a: significant at $p<0.05$ vs. control. 


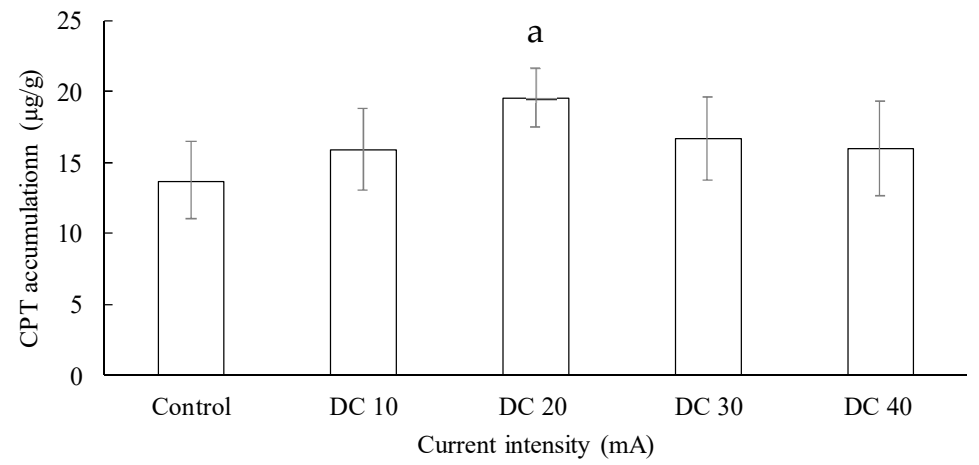

Figure 9. Effects of DC intensities (10, 20, 30 and $40 \mathrm{~mA}$ ) on CPT accumulation in O. ridleyana leaves. The values are expressed as mean $\pm \mathrm{SD}(n=3)$; a: significant at $p<0.05$ vs. control.

The HPLC chromatograms obtained from O. ridleyana roots of those treated with DC $20 \mathrm{~mA}$ showed a much larger peak area than those of the untreated controls (Supplementary Materials). It was also demonstrated that CPT concentrations in roots of all treated plants by DC stimulation were significantly higher in comparison to that of the untreated plant, which contained CPT at $27.3 \mu \mathrm{g} / \mathrm{g}$ DW.

\subsubsection{Stems}

Compared to the control, by the DC stimulation, the CPT concentrations in O. ridleyana stems of all treated plants were relatively higher (Figure 8, Table 4). Significant higher CPT concentrations were obtained by DC stimulation at $20 \mathrm{~mA}$ and $30 \mathrm{~mA}$, which were 36.0 and $31.8 \mu \mathrm{g} / \mathrm{g}$ DW, respectively, whereas that of untreated plant was $21.3 \mu \mathrm{g} / \mathrm{g}$ DW. The results, therefore, indicate that the electrical treatment is a promising tool to induce secondary metabolites in plant cells.

\subsubsection{Leaves}

The CPT concentrations in O. ridleyana leaves of all treated plants were also relatively higher than that of the control plants (Figure 9 and Table 4). The DC stimulation at $20 \mathrm{~mA}$ resulted in a significant increase in CPT content $(19.6 \mu \mathrm{g} / \mathrm{g}$ DW) compared to the nontreated plants $(13.8 \mu \mathrm{g} / \mathrm{g} \mathrm{DW})$. In this study, the electrical stimulation could effectively promote CPT accumulation in all parts of the treated tissue culture plants (roots, stems and leaves) of tissue culture plants of $O$. ridleyana Craib, but MeJA elicitation was found to promote CPT accumulation only in roots and stems.

Overall, by means of the DC stimulation at $20 \mathrm{~mA}$, the total CPT accumulation of 5-month-old tissue culture plants of O. ridleyana in solid medium was increased to $8.4 \mu \mathrm{g} /$ bottle, which was by approximately 1.5 -fold increase as compared to that of the control.

\section{Discussion}

Tissue-culture plants can be exploited as an ecofriendly approach to produce secondary metabolites in vitro and protect endangered plants from extinction. The present results demonstrated the development of plant science technologies to enhance the productivity of CPT from O. ridleyana plants in vitro. Without the elicitation, the accumulation of CPT of 5-month-old tissue-culture plants of $O$. ridleyana was higher in roots, followed by stems and the leaves, respectively. Previously, Roja [12] reported CPT contents in plants of O. rugosa at $0.002 \%$ DW in roots, trace quantities in stems, and $0.0002 \%$ DW in leaves. Significant improvement in CPT production was attained by simple pouring of MeJA solution of $50 \mu \mathrm{M}$ onto the surface of the solid medium and incubation for $12 \mathrm{~h}$ before harvesting, in which the CPT contents in roots and stems were at approximately 1.8- and 2.6- fold increase, respectively compared with that of the controls. The higher CPT content in roots and stems can be explained from the role of MeJA as a signal compound responsible for the induction of signal transduction, the expression of many defense genes followed by the 
accumulation of secondary metabolites in plants. MeJA could act as a signal transducer in the enhancement of alkaloid biosynthesis. Previously, upon elicitation of hairy roots in a liquid medium, MeJA significantly enhances alkaloid production, particularly CPT in $O$. liukiuensis hairy roots; however, this effect is not observed in O. kuroiwai and O. pumila [4]. On the other hand, elicitation by salicylic acid and yeast extract showed a repressive effect on alkaloid production [4]. The present results are also compatible with previous research by $\mathrm{Xu}$ et al. [30], who observed an increase in triterpenoids production in shake flask cultures of Inonotus obliquus in response to addition of MeJA as an exogenous elicitor and fatty acids as a stimulatory agent in liquid medium; the optimal elicitor concentration was $50 \mu \mathrm{M}$ MeJA. After elicitation for $6 \mathrm{~d}$, the production of total triterpenoids was increased by $66 \%$ compared with that of the control. The kinetics of CPT accumulation in suspension cultures of Camptotheca acuminate in response to elicitation with jasmonic acid showed that CPT accumulation peaked at $4 \mathrm{~d}$ after treatment and thereafter, the CPT concentration rapidly decreased [11]. Previously, increased CPT production in multiple shoot cultures of $O$. mungos elicited with $150 \mu \mathrm{M}$ MeJA in $1 / 2 \mathrm{MS}$ liquid medium for $72 \mathrm{~h}$ was also reported [21]. In the present study, the maximum increase in CPT content in the roots and stems of tissue-cultured plants of $O$. ridleyana in $1 / 2 \mathrm{MS}$ solid medium was observed after the elicitation with $50 \mu \mathrm{M}$ MeJA for $12 \mathrm{~h}$. However, no significant difference was noticed from the elicitation with pure ethanol. Ethanol has been reported as a small-molecule elicitor, which could alter the expression of secondary metabolic genes in tissue cultures of certain plant species. It was previously reported that addition of absolute ethanol (up to $5 \% \mathrm{v} / \mathrm{v}$ ) to the suspension culture of Fusarium solani results in enhanced CPT production compared with that of the control [7]. However, in the current study, no significant effect of ethanol on CPT production by tissue-cultured plants of $O$. ridleyana was observed in vitro. These different responses may reflect differences in plant species, age of plants, cultivation methods, and elicitation procedures.

Under the 20 and $50 \mu \mathrm{M}$ MeJA treatments, only slight increases in CPT content in the leaves was observed. Accumulation of secondary plant metabolites, triterpenoids in Centella asiatica leaves might be triggered by postharvest application of MeJA [31]. However, in a study of the distribution of strictosidine synthase (STR), a crucial enzyme for CPT biosynthesis in different tissues of O. pumila, STR activity was detected in stem, root, and hairy root extracts, but no activity was detected in leaf and callus extracts [1]. It has been suggested that roots and stems are the predominant tissues in which CPT biosynthesis occurs [1]. The distribution of STR activity is correlated with the accumulation of mRNA and CPT production in O. pumila tissues. Presence of MeJA as a signaling molecule on the plasma membrane could initiate a signal transduction network inside the cells, leading to the expression of biosynthetic genes involved in the production of plant secondary metabolites of CPT in Ophiorrhiza [21,32]. In the present study, following elicitation with MeJA $(50 \mu \mathrm{M})$ for $12 \mathrm{~h}$, the total CPT accumulation of whole plants of 5-month-old $O$. ridleyana cultured in vitro in solid medium was increased by approximately 1.8 -fold as compared with that of the control (Table 3). In comparison with plant tissue culturing in liquid medium, plant culture on solid medium is simpler, requires less expensive equipment, consumes less energy, and is easier for large-scale production.

Furthermore, the use of electrical stimulation for CPT accumulation in tissue culture plants of $O$. ridleyana was investigated. The DC current at 10-40 mA with the total treatment time of $15 \mathrm{~min}$ was applied to 5-month-old $O$. ridleyana plants in vitro. Effects of electrical stimulation on some secondary plant metabolisms have been previously reported. Enhanced lycopene, $\beta$-carotene, total phenols contents and antioxidant activity were attained with a DC treatment of $500 \mathrm{~mA}$ with an application time of 15-30 min on Solanum Lycopersicon L. after an adaptation time of 2-24 h [27]. Electrical stimulation was also found to increase anthocyanin and resveratrol contents in berries of grapevines relative to those of control plants and electrode-treated plants [33]. Previously, the treatment by DC current demonstrated effects on the accumulation of some bioactive compounds in leaves. Applied DC induced alteration of cell membrane permeability due to DC could 
have improved physiological processes, leading to enhanced accumulation of bioactive compounds such as chlorophylls carolenoids in African nightshade leaves [28]. Biosynthesis of secondary plant compounds is usually associated with plant defense response. Plant defense response can be induced by an elicitor and/or physiological stimulation such as changes in membrane potential and ion fluxes to trigger oxidative burst, resulting in the activation of defense-related genes for synthesis of secondary compounds [26,34]. It was suggested that DC influences the voltage-gated ion channels and increases the membrane permeability for calcium cations $\left(\mathrm{Ca}^{2+}\right)$ at the cellular level, followed by a rapid influx of $\mathrm{Ca}^{2+}$ through cation channels. Voltage-gated calcium $\left(\mathrm{Ca}^{2+}\right)$ channels are key transducers of membrane potential changes into intracellular $\mathrm{Ca}^{2+}$ transients that initiate many physiological events. $\mathrm{Ca}^{2+}$ plays an important role in signal transduction and in the absorption of nutrients across the cell membranes [35,36] and helps in the upregulation of respective genes for biosynthesis of secondary metabolites in plants such as polyphenols, flavonoid [37]. Therefore, electrical stimulation could be considered as physiological stimulation to induce plant secondary metabolism. The additional potential induced from external electric field in plants was reported to raise pressure on the membrane due to attraction between opposite charges on both sides of the membrane, whereby a faster transport of ions was induced simultaneously and this could cause an accumulation of minerals and bioactive compounds [28]. In the present study, the treatment by applied DC current at $20 \mathrm{~mA}$ could enhance the CPT content in roots, stems and leaves at 1.5-, 1.7- and 1.4-fold higher than that of the controls, respectively. The results indicate that electrical stimulation is also a promising tool to induce secondary metabolites in plant cells. The modified techniques used in this work are also of interest for potential application to other plant secondary metabolite production. The proposed procedures should be beneficial for the preharvest treatment of tissue-cultured plants to stimulate biosynthesis of secondary metabolic products. However, the detailed mechanism for electrical stimulation of plant tissue cultures to enhance the production of bioactive secondary metabolites is still unclear and needs further study.

Supplementary Materials: The following are available online at https:/ / www.mdpi.com/article / 10.3390/app11104555/s1, Figure S1: HPLC chromatograms of the extracts of O. ridleyana on CPT content detected at $254 \mathrm{~nm}$ : (A) extracts from roots of the untreated controls, and (B) extracts from roots of the treated tissue-cultured plants with $50 \mu \mathrm{M} \mathrm{MeJA}$ and incubation for $12 \mathrm{~h}$, Figure S2: HPLC chromatograms of the extracts of O. ridleyana on CPT content detected at $254 \mathrm{~nm}$ : (A) extracts from roots of the untreated controls, and (B) extracts from roots of those treated by electrical stimulation with DC $20 \mathrm{~mA}$.

Author Contributions: Conceptualization, M.P. and S.S.; methodology, M.P., S.S., K.K. and S.P.; validation, M.P. and S.S.; formal analysis, S.P.; investigation, M.P., S.S. and S.P.; resources, M.P. and S.S.; data curation, S.P.; writing—original draft preparation, S.P.; writing—review and editing, M.P. and S.S.; supervision, M.P. and S.S.; project administration, M.P. and S.S.; funding acquisition, M.P. and S.S. All authors have read and agreed to the published version of the manuscript.

Funding: This research was funded by the 90th Anniversary of Chulalongkorn University Fund (Ratchadaphiseksomphot Endowment Fund).

Institutional Review Board Statement: Not applicable.

Informed Consent Statement: Not applicable.

Data Availability Statement: The data presented in this study are available on request from the corresponding author.

Acknowledgments: This work is financially supported by the 90th Anniversary of Chulalongkorn University Fund (Ratchadaphiseksomphot Endowment Fund).

Conflicts of Interest: The authors declare no conflict of interest. 


\section{References}

1. Yamazaki, Y.; Urano, A.; Sudo, H.; Kitajima, M.; Takayama, H.; Yamazaki, M.; Aimi, N.; Saito, K. Metabolite profiling of alkaloids and strictosidine synthase activity in camptothecin producing plants. Phytochemistry 2003, 62, 461-470. [CrossRef]

2. Chavan, S.P.; Pasupathy, K.; Venkatraman, M.S.; Kale, R.R. Formal total synthesis of camptothecin via ring-closing metathesis strategy. Tetrahedron Lett. 2004, 45, 6879-6882. [CrossRef]

3. Martino, E.; Volpe, S.D.; Terribile, E.; Benetti, E.; Sakaj, M.; Centamore, A.; Sala, A.; Collina, S. The long story of camptothecin: From traditional medicine to drugs. Bioorganic Med. Chem. Lett. 2017, 27, 701-707. [CrossRef]

4. Asano, T.; Watase, I.; Sudo, H.; Kitajima, M.; Takayama, H.; Aimi, N.; Yamazaki, M.; Saito, K. Camptothecin production by in vitro cultures of Ophiorhiza liukiuensis and O. Kuroiwai Plant Biotechnol. 2004, 21, 275-281. [CrossRef]

5. Deephi, S.; Satheeshkumar, K. Effects of major nutrients, growth regulators and inoculum size on enhanced growth and camptothecin production in adventitious root cultures of Ophiorrhiza mungos L. Biochem. Eng. J. 2017, 117, 198-209. [CrossRef]

6. Watase, I.; Sudo, H.; Yamazaki, M.; Saito, K. Regeneration of transformed Ophiorrhiza pumila plants producing camptothecin. Plant Biotechnol. 2004, 21, 337-342. [CrossRef]

7. Venugopalan, A.; Srivastava, S. Enhanced camptothecin production by ethanol addition in the suspension culture of the endophyte. Fusarium Solani Bioresour. Technol. 2015, 188, 251-257. [CrossRef] [PubMed]

8. Liu, Y.Q.; Li, W.Q.; Morris-Natschke, S.L.; Qian, K.; Yang, L.; Zhu, G.X.; Wu, X.B.; Chen, A.L.; Zhang, S.Y.; Nan, X.; et al. Perspective on biologically active camptothecin derivatives. Med. Res. Rev. 2015, 35, 753-789. [CrossRef]

9. Deephi, S.; Satheeshkumar, K. Enhanced camptothecin production induced by elicitors in the cell suspension cultures of Ophiorrhiza mungos Linn. Plant Cell Tissue Organ Cult. 2016, 124, 483-493. [CrossRef]

10. Ya-ut, P.; Chareonsap, P.; Sukrong, S. Micropropagation and hairy root culture of Ophiorrhiza alata Craib for camptothecin production. Biotechnol. Lett. 2011, 33, 2519-2526. [CrossRef] [PubMed]

11. Song, S.H.; Byun, S.Y. Elicitation of camptothecin production in cell cultures of Camptotheca acuminata. Biotechnol. Bioprocess Eng. 1998, 3, 91-95. [CrossRef]

12. Roja, G. Micropropagation and production of camptothecin from in vitro plants of Ophiorrhiza rugose var. decumbens. Nat. Prod. Res. 2008, 22, 1017-1023. [CrossRef] [PubMed]

13. Martin, K.P.; Zhang, C.L.; Hembrom, M.E.; Slater, A.; Madassery, J. Adventitious root induction in Ophiorrhiza prostrata: A tool for the production of camptothecin (an anticancer drug) and rapid propagation. Plant Biotechnol. Rep. 2008, 2, 163-169. [CrossRef]

14. Asano, T.; Kobayashi, K.; Kashihara, E.; Sudo, H.; Sasaki, R.; Lijima, Y.; Aoki, K.; Shibata, D.; Saito, K.; Yamazaki, M. Suppression of camptothecin biosynthetic genes results in metabolic modification of secondary products in hairy roots of Ophiorrhiza pumila. Phytochemistry 2013, 91, 128-139. [CrossRef] [PubMed]

15. Putalun, W.; Luealon, W.; De-Eknamkul, W.; Tanaka, H.; Shoyama, Y. Improvement of artemisinin production by chitosan in hairy root cultures of Artemisia annua L. Biotechnol. Lett. 2007, 29, 1143-1146. [CrossRef] [PubMed]

16. Shohael, A.M.; Murthy, H.N.; Hahn, E.J.; Lee, H.L.; Paek, K.Y. Increased elutheroside production in Eleutherococus sessiliflorus embryogenic suspention cultures with methyl jasmonate treatment. Biochemical. Eng. J. 2008, 38, 270-273. [CrossRef]

17. Sakunphueak, A.; Panichayupakaranant, P. Increased production of naphthoquinones in Impatiens balsamina root cultures by elicitation with methyl jasmonate. Bioresour. Technol. 2010, 101, 8777-8783. [CrossRef]

18. Linden, J.C.; Phisalaphong, M. Oligosaccharides potentiate methyl jasmonate-induced production of paclitaxel in Taxus Canadensis. Plant Sci. 2000, 158, 41-51. [CrossRef]

19. Shabani, L.; Ehsanpour, A.A.; Asghari, G.; Emami, J. Glycyrrhizin production by in vitro cultured Glycyrrhiza glabra elicited by methyl jasmonate and salicylic acid. Russ. J. Plant Physiol. 2009, 56, 621-626. [CrossRef]

20. Phisalaphong, M.; Linden, J.C. Kinetic studies of paclitaxel production by Taxus canadensis cultures in batch and semicontinuous with total cell recycle. Biotechnol. Prog. 1999, 15, 1072-1077. [CrossRef]

21. Krishnan, J.J.; Gangaprasad, A.; Satheeshkumar, K. Exogenous methyl jasmonate acts as a signal transducer in the enhancement of camptothecin (CPT) production from in vitro cultures of Ophiorrhiza mugos L. var. augustifolia (Thw.) Hook. f. Ind. Crop. Prod. 2018, 119, 93-101. [CrossRef]

22. Putalun, W.; Udomsin, O.; Yusakul, G.; Juengwatanatrakul, T.; Sakamoto, S.; Tanaka, H. Enhanced plumbagin production from in vitro cultures of Drosera burmunii using elicitation. Biotechnol. Lett. 2010, 32, 721-724. [CrossRef]

23. Flores, G.; Ruiz del Castillo, M.L. Influence of preharvest and postharvest methyl jasmonate treatments on flovonoid content and metabolomic enzymes in red rasberry. Postharvest Biol. Technol. 2014, 97, 77-82. [CrossRef]

24. Buchmann, L.; Mathys, A. Perspective on Pulsed Electric Field Treatment in the Bio-based Industry. Front. Bioeng. Biotechnol. 2019, 7, 1-7. [CrossRef]

25. Dannehl, D. Effects of electricity on plant responses. Sci. Hortic. 2018, 234, 382-392. [CrossRef]

26. Ye, H.; Huang, L.-L.; Chen, S.-D.; Zhong, J.-J. Pulsed electric field stimulates plant secondary metabolism in suspension cultures of Taxus chinensi. Biotechnol. Bioeng. 2004, 88, 788-795. [CrossRef]

27. Dannehl, D.; Huyskens-Keil, S.; Eichholz, I.; Ulrichs, C.; Schmidt, U. Effects of direct-electric-current on secondary plant compounds and antioxidant activity in harvested tomato fruits (Solanum Lycopersicon L.). Food Chem. 2011, 126, 157-165. [CrossRef]

28. Gogo, E.O.; Huyskens-keil, S.; Krimlowski, A.; Ulrichs, C. Impact of direct-electric-current on growth and bioactive compounds of African nightshade (Solanum scabrum Mill.) plants. J. Appl. Bot. Food Qual. 2016, 89, 60-67. [CrossRef] 
29. Leong, S.Y.; Burritt, D.J.; Oey, I. Evaluation of the anthocyanin release and health-promoting properties of Pinot Noir grape juices after pulsed electric fields. Food Chem. 2016, 196, 833-841. [CrossRef] [PubMed]

30. Xu, X.; Zhang, X.; Chen, C. Stimulated production of triterpenoids of Inonotus obliquus methyl jasmonate and fatty acids. Ind. Crop. Prod. 2016, 85, 49-57. [CrossRef]

31. Buraphaka, H.; Putalun, W. Stimulation of health-promoting triterpenoids accumulation in Centella asiatica (L.) Urban leaves triggered by postharvest application of methyl jasmonate and salicylic acid elicitors. Ind. Crop. Prod. 2020, 146, 112171. [CrossRef]

32. Zhao, J.; Davis, L.C.; Verpoorte, R. Elicitor signal transduction leading to production of plant secondary metabolites. Biotechnol. Adv. 2005, 23, 283-333. [CrossRef]

33. Mikami, M.; Mori, D.; Masumura, Y.; Aoki, Y.; Suzuki, S. Electrical stimulation: An abiotic stress generator for enhancing anthocyanin and resveratrol accumulation in grape berry. Sci. Hortic. 2017, 226, 285-292. [CrossRef]

34. Low, P.S.; Merida, J.R. The oxidative burst in plant defense: Function and signal transduction. Physiol. Plant 1996, 96, 533-542. [CrossRef]

35. White, P.J. Calcium channels in higher plants. Biochim. Biophys. Acta Biomembr. 2000, 1465, 171-189. [CrossRef]

36. Ahmad, P.; Abdel Latef, A.A.; Abd Allah, E.F.; Hashem, A.; Sarwat, M.; Anjum, N.A.; Gucel, S. Calcium and potassium supplementation enhanced growth, osmolyte secondary metabolite production, and enzymatic antioxidant machinery in cadmium exposed chickpea (Cicer arietinum L.). Front. Plant Sci. 2016, 7, 513. [CrossRef]

37. Xu, W.; Peng, H.; Yang, T.; Whitaker, B.; Huang, L.; Sun, J.; Chen, P. Effect of calcium on strawberry fruit flavonoid pathway gene expression and anthocyanin accumulation. Plant Physiol. Bioch. 2014, 82, 289-298. [CrossRef] [PubMed] 